Research Paper

\title{
Comparison of Biochemical Recurrence After Robot-assisted Laparoscopic Radical Prostatectomy with Volatile and Total Intravenous Anesthesia
}

\author{
Na Young Kim ${ }^{1 *}$, Won Sik Jang ${ }^{2 *}$, Young Deuk Choi², Jung Hwa Hong ${ }^{3}$, Sewon Noh${ }^{1}$, Young-Chul Yoo ${ }^{\circledR}$ \\ 1. Department of Anesthesiology and Pain Medicine, Anesthesia and Pain Research Institute, Yonsei University College of Medicine, Seoul, Republic of Korea. \\ 2. Department of Urology and Urological Science Institute, Yonsei University College of Medicine, Seoul, Republic of Korea. \\ 3. Department of Policy Research Affairs National Health Insurance Service Ilsan Hospital, Goyang, Gyeonggi-do, Republic of Korea. \\ * These authors contributed equally to this work. \\ $\triangle$ Corresponding author: Young-Chul Yoo MD, PhD, Department of Anesthesiology and Pain Medicine, Anesthesia and Pain Research Institute, Yonsei \\ University College of Medicine, 50-1 Yonsei-ro, Seodaemun-gu, Seoul 03722, Republic of Korea. Phone: 82-2-2228-2440. Fax: 82-2-312-7185. E-mail: \\ SEAOYSTER@yuhs.ac.
}

(c) The author(s). This is an open access article distributed under the terms of the Creative Commons Attribution License (https://creativecommons.org/licenses/by/4.0/). See http:/ /ivyspring.com/terms for full terms and conditions.

Received: 2019.10.07; Accepted: 2020.01.08; Published: 2020.02.04

\begin{abstract}
Aims: Recurrence after cancer surgery is a major concern in patients with cancer. Growing evidence from preclinical studies has revealed that various anesthetics can influence the immune system in different ways. The current study compared the long-term biochemical recurrence of prostate cancer after robot-assisted laparoscopic radical prostatectomy (RALP) in terms of selection of anesthetic agent between total intravenous anesthesia (TIVA) with propofol/remifentanil and volatile anesthetics (VA) with sevoflurane or desflurane/remifentanil.

Methods: We followed up oncologic outcomes of patients who underwent RALP from two previous prospective randomized controlled trials, and the outcomes of those who received TIVA $(n=64)$ were compared with those who received VA $(n=64)$. The follow-up period lasted from November 2010 to March 2019.

Results: Both TIVA and VA groups showed identical biochemical recurrence-free survivals at all-time points after RALP. The following predictive factors of prostate cancer recurrence were determined by Cox regression: colloid input [hazard ratio $(\mathrm{HR})=1.002,95 \%$ confidence interval $(\mathrm{Cl}): 1.000-1.003 ; \mathrm{P}=$ 0.011 ], initial prostate-specific antigen level $(H R=1.025,95 \% \mathrm{Cl}: 1.007-1.044 ; P=0.006)$, and pathological tumor stage $3 \mathrm{~b}(\mathrm{HR}=4.217,95 \% \mathrm{Cl}: 1.207-14.735 ; \mathrm{P}=0.024)$, but not the anesthetic agent.

Conclusions: Our findings demonstrate that both TIVA with propofol/remifentanil and VA with sevoflurane or desflurane/remifentanil have comparable effects on oncologic outcomes in patients undergoing RALP.
\end{abstract}

Key words: Prostate cancer, recurrence, propofol, volatile, anesthesia.

\section{Introduction}

A major concern among patients with cancer is recurrence after cancer surgery. Aside from several well-documented factors that synergistically influence the risk of long-term cancer recurrence, recent studies have shown that anesthetic agents might affect the postoperative prognosis of cancer due to its unfavorable effect on the immune system [1,2], and has led to a renewed interest in this field [3].
Propofol has been reported to exhibit positive immunomodulatory effects [3-5], and better survival has been reported after cancer surgery with propofol-based total intravenous anesthesia (TIVA) compared to volatile anesthesia (VA) [6-9]. However, other recent studies have yielded different results regarding the influence of anesthetic agents on the recurrence of breast cancer [10, 11], and different 
oncologic outcomes have been demonstrated depending on the type of cancer [7, 11-14].

Currently, the most common malignancy among males in the United States is prostate cancer [15], with over 160,000 new cases diagnosed in 2018 and almost 30,000 resultant deaths [16]. Until now, there have been no studies of the influence of anesthetic agents on the recurrence of prostate cancer. We previously published two prospective randomized controlled trials, which were conducted to compare postoperative nausea and vomiting (PONV) and changes in intraocular pressure (IOP) in patients who underwent robot-assisted laparoscopic radical prostatectomy (RALP) under general anesthesia with either propofol-based TIVA or sevoflurane-based VA $[17,18]$. The patients who participated in these two studies underwent RALP 7-9 years ago, providing a unique opportunity to assess their cancer status and long-term survival.

Thus, this study aimed to compare the effects of VA with sevoflurane or desflurane/remifentanil and TIVA with propofol/remifentanil on long-term oncologic outcomes, such as biochemical recurrence (BCR), in patients with prostate cancer after RALP.

\section{Materials and Methods}

\section{Study design and participants}

Detailed descriptions of the design of the previous trials (PONV and IOP) have been published previously $[17,18]$. PONV and IOP were randomized controlled trials that evaluated and compared the effects of VA with sevoflurane or desflurane/ remifentanil and TIVA with propofol/remifentanil on PONV and the changes of IOP in patients undergoing RALP. Sixty-two patients between November 2010 and May 2011, and 66 patients between May 2011 and Mar 2012, were enrolled in the PONV and IOP trials, respectively. Additional ethics approvals for the follow-up study were obtained from the institutional review board (IRB) and hospital research ethics committee (Yonsei University Health System, Seoul, Korea; IRB protocol No. 4-2019-0313, approved on 23 May, 2019). The need for informed consent from the patients was waived. Patients were followed up from November 2010 to March 2019. Additional criterion for enrolment in the follow-up study included patients who underwent complete surgical excision of prostate cancer without any surgical complications. Patients with uncertain clinical conditions or incomplete follow-up data were excluded. For this follow-up study, BCR status, prostate specific antigen (PSA) levels, and TNM staging of tumor were collected at time points after the original trials.

\section{Anesthesia protocol}

Premedication was performed with $0.05 \mathrm{mg} / \mathrm{kg}$ midazolam and $0.2 \mathrm{mg}$ glycopyrrolate 1 hour before and immediately before the initiation of anesthesia, respectively. Standard monitoring with non-invasive blood pressure, electrocardiography, and saturation was conducted. Anesthesia was induced with propofol and remifentanil in both groups. After loss of consciousness, $0.6 \mathrm{mg} / \mathrm{kg}$ rocuronium was administered to facilitate tracheal intubation. Controlled ventilation was performed with $40 \%$ oxygen in air to maintain end tidal carbon dioxide $\left(\mathrm{CO}_{2}\right)$ at $35-40 \mathrm{mmHg}$ during the surgery, and a positive end-expiratory pressure of $5 \mathrm{~cm} \mathrm{H}_{2} \mathrm{O}$ was applied. Body temperature was maintained at $36-37^{\circ} \mathrm{C}$ using a forced-air warming system. For continuous blood pressure monitoring, 20-G radial artery catheterization was performed in all patients.

In the VA group, anesthesia was induced with an intravenous bolus of propofol $(1.5 \mathrm{mg} / \mathrm{kg})$ and maintained with sevoflurane $(1.5-2.5 \%)$ or desflurane $(4-7 \%)$. In the TIVA group, propofol was administered using a TCI pump (Orchestra ${ }^{\circledR}$ Base Primea, Fresenius Vial, France) according to the Marsh model. [19] The target plasma concentration of propofol was maintained within 2-5 $\mu \mathrm{g} / \mathrm{mL}$. Remifentanil was administered to all patients using a TCI pump, according to the Minto model [20], and the effect-site concentration was adjusted to within 2-5 $\mathrm{ng} / \mathrm{mL}$. The anesthetics administered to each group were titrated to maintain mean arterial pressure (MAP) and heart rate within $20 \%$ of baseline values and to provide adequate depth of anesthesia. A bispectral index score (BIS) monitor (Aspect A-2000®, Aspect Medical System Inc., Newton, MA, USA) was used so that the BIS could be maintained within the range of $40-60$. Additional boluses of $0.15 \mathrm{mg} / \mathrm{kg}$ rocuronium were administered as needed to maintain adequate intraoperative neuromuscular blockade. During the operation, $\mathrm{CO}_{2}$ pneumoperitoneum was induced to maintain a mean (standard deviation, SD) intra-abdominal pressure of 15 (5) $\mathrm{mmHg}$ using a $\mathrm{CO}_{2}$ insufflator in a $30^{\circ}$ Trendelenburg position. The Trendelenburg angle was accurately adjusted by the operating table controller, which showed the tilted angle in numbers.

All patients received $0.3 \mathrm{mg}$ ramosetron intravenously 20 minutes before the end of surgery, and postoperative pain was controlled using intravenous patient-controlled analgesia (PCA), consisting of $20 \mu \mathrm{g} / \mathrm{kg}$ fentanyl mixed with normal saline to a total volume of $100 \mathrm{ml}$, administered at a basal rate of $2 \mathrm{ml} / \mathrm{h}$, with a bolus dose of $0.5 \mathrm{ml}$ and a 15-min lockout time. At the end of surgery, reversal of neuromuscular blockade was performed with 50 
$\mu \mathrm{g} / \mathrm{kg}$ neostigmine and $10 \mu \mathrm{g} / \mathrm{kg}$ glycopyrrolate intravenously. After extubation and when fully awake, the patients were transported to the post-anesthesia care unit.

\section{Statistical Analysis}

The primary endpoint of the study was the effects of VA with sevoflurane or desflurane/ remifentanil and TIVA with propofol/remifentanil on BCR in patients after RALP. Patients were followed up with serum PSA tests at 3-month intervals for the first 2 years, at 6-month intervals for the next 3 years, and annually thereafter. BCR was defined as two consecutive rises in serum PSA levels $\geq 0.2 \mathrm{ng} / \mathrm{ml}$ at any time postoperatively. Continuous variables are presented as means (SD), and categorical variables are presented as numbers of patients (percentages). Continuous variables were compared using independent $t$-tests, and categorical variables were compared using the chi-square test or Fisher's exact test. Kaplan-Meier curves were calculated based on the occurrence of BCR for each period $(12,24,36$ months, and overall), and the groups were compared using the log-rank test. Cox proportional hazard regression was performed to identify associated independent factors, and the results are presented as hazard ratios (HRs) and 95\% confidence intervals (CIs). SAS version 9.4 (SAS Institute Inc., Cary, NC, USA) was used for all statistical analyses. A $p$-value < 0.05 was considered statistically significant.

\section{Results}

Out of 128 patients who were enrolled in both prospective randomized trials (62 and 66 eligible patients in the PONV and IOP trials, respectively), two patients with follow-up loss were excluded from the VA group. The final sample for analysis included 126 patients who had been assigned to either the TIVA $(n=64)$ or the VA $(n=62)$ group (Figure 1$)$.

Table 1 shows the distribution of demographics and perioperative variables in both groups. As is expected from the randomized study design, baseline characteristics of the two groups were comparable. In the VA group, two volatile agents were used: 31 patients received sevoflurane and 31 patients received desflurane, with BCR observed in 13 patients (42\%) receiving sevoflurane and in 15 patients (48\%) receiving desflurane. There was no significant difference in the incidence of BCR between the two volatile agents in the VA group $(\mathrm{P}=0.799)$.

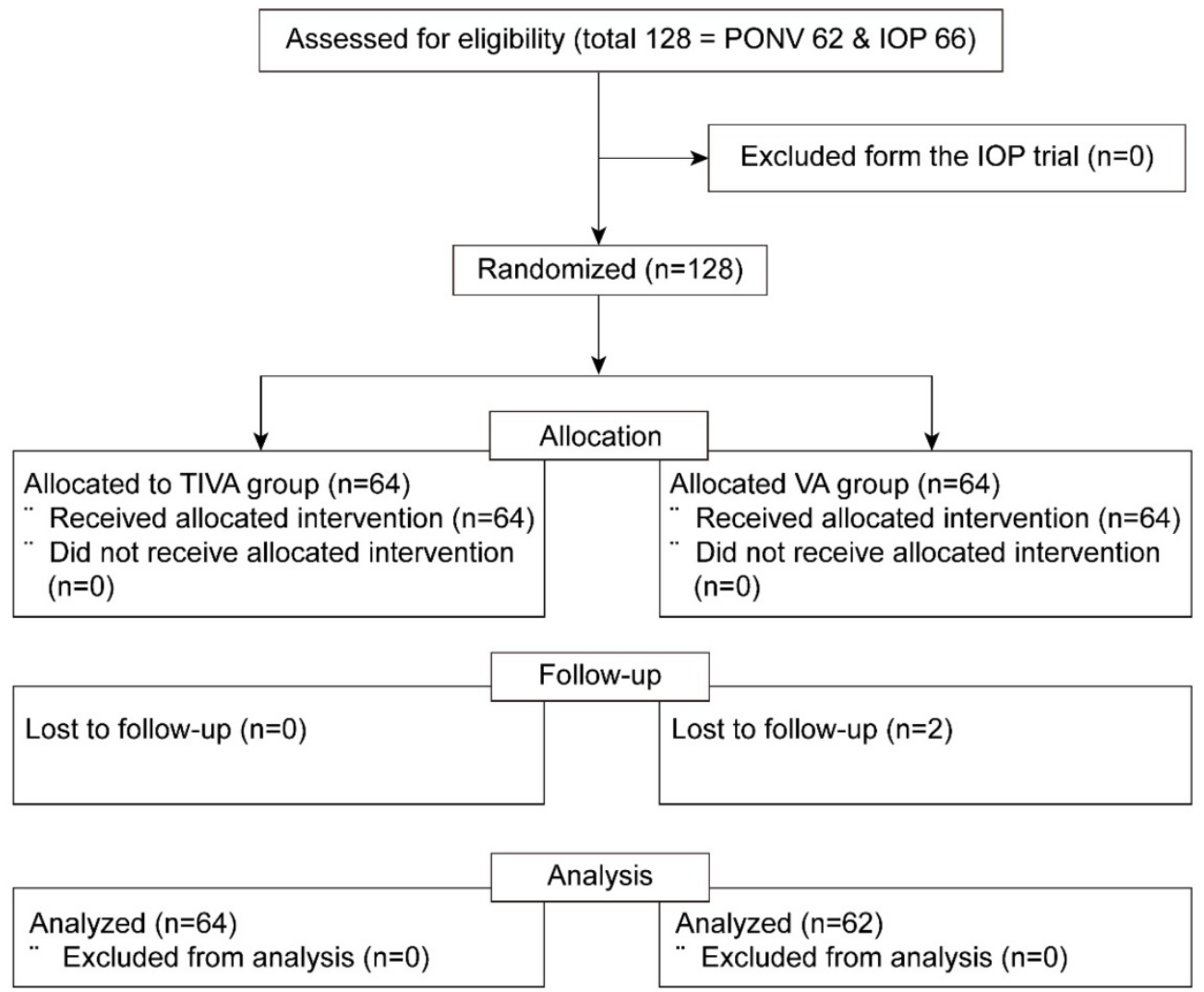

Figure 1. Consort flow diagram. PONV = postoperative nausea and vomiting; IOP = intraocular pressure; TIVA = total intravenous anesthesia; VA = volatile anesthesia 
A

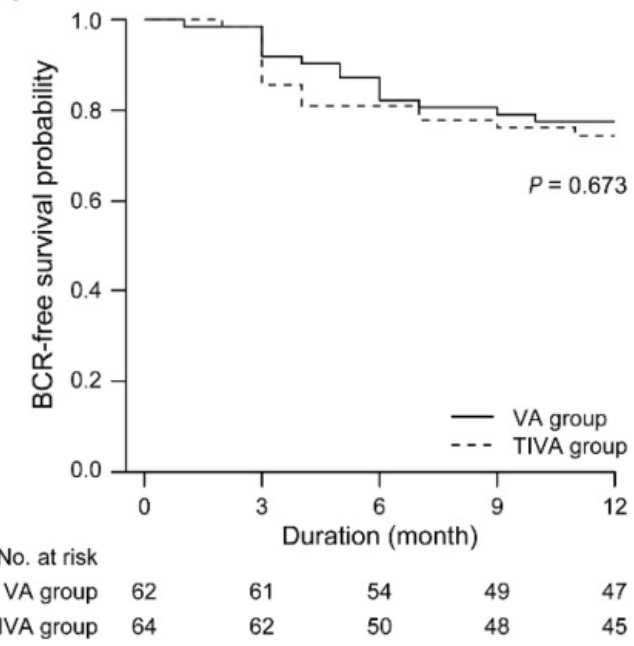

C

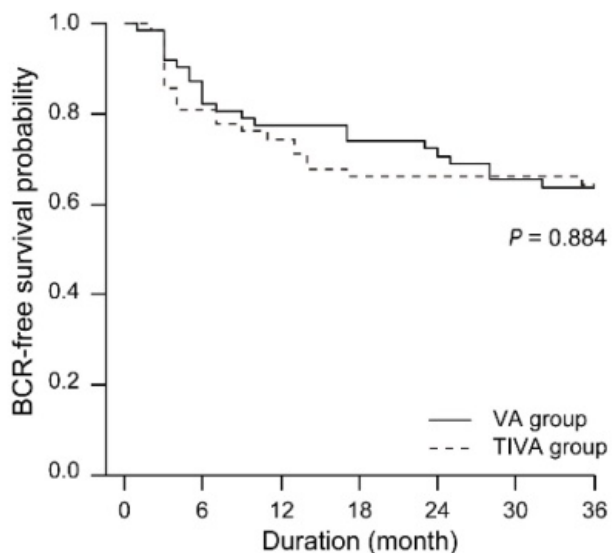

No. at risk

$\begin{array}{llllllll}\text { VA group } & 62 & 54 & 47 & 45 & 43 & 37 & 36\end{array}$

$\begin{array}{llllllll}\text { TIVA group } & 64 & 50 & 45 & 39 & 37 & 35 & 33\end{array}$
B

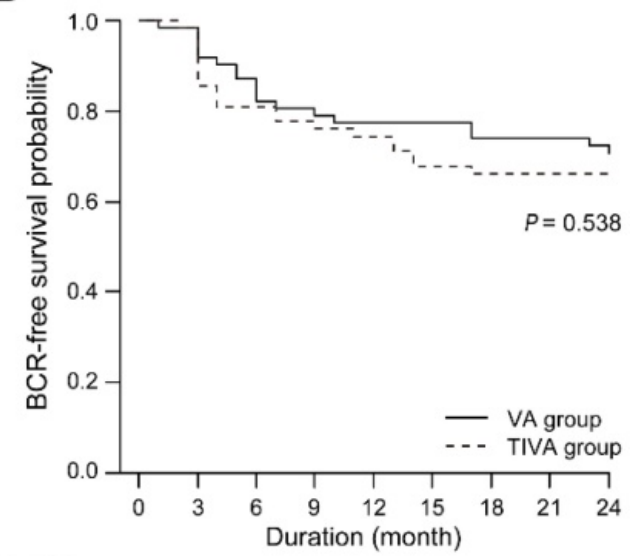

No. at risk

$\begin{array}{llllllllll}\text { VA group } & 62 & 61 & 54 & 49 & 47 & 47 & 45 & 45 & 43\end{array}$ $\begin{array}{llllllllll}\text { TIVA group } & 64 & 62 & 50 & 48 & 45 & 41 & 39 & 38 & 37\end{array}$

D

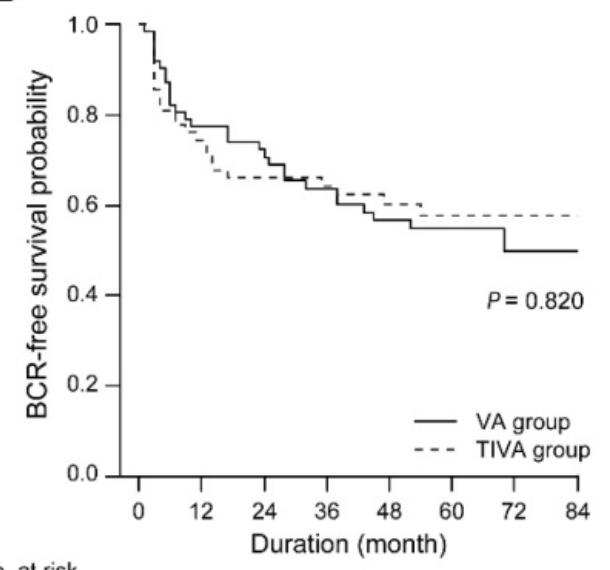

No. at risk

$\begin{array}{lllllllll}\text { VA group } & 62 & 47 & 43 & 36 & 31 & 20 & 9 & 4\end{array}$

$\begin{array}{lllllllll}\text { TIVA group } & 64 & 45 & 37 & 33 & 27 & 18 & 11 & 4\end{array}$

Figure 2. $B C R$-free survival between the TIVA and VA groups at any follow-up point after RALP. IOP = intraocular pressure; TIVA = total intravenous anesthesia; $V A=$ volatile anesthesia; $B C R=$ biochemical recurrence.

Table 1. Demographics and perioperative variables.

\begin{tabular}{|c|c|c|c|}
\hline Variables & $\begin{array}{l}\text { VA group } \\
(\mathrm{n}=62)\end{array}$ & $\begin{array}{l}\text { TIVA group } \\
(\mathrm{n}=64)\end{array}$ & P value \\
\hline Age, years & $62.9(7.1)$ & $63.9(8.0)$ & 0.497 \\
\hline Height, $\mathrm{m}^{2}$ & $168.1(5.2)$ & $167.9(6.9)$ & 0.776 \\
\hline Weight, kg & $69.3(10.3)$ & $69.1(9.4)$ & 0.920 \\
\hline ASA physical status & & & 0.702 \\
\hline I & $26(42 \%)$ & $29(45 \%)$ & \\
\hline II & $36(58 \%)$ & $35(55 \%)$ & \\
\hline Sevoflurane/Desflurane, $\mathrm{n}$ & $31 / 31$ & & \\
\hline Anesthesia time, min & $190.4(40.4)$ & $192.1(45.2)$ & 0.821 \\
\hline Pneumoperitoneum time, min & $114.7(36.3)$ & $118.9(40.8)$ & 0.546 \\
\hline \multicolumn{4}{|l|}{ Intraoperative input \& Output } \\
\hline Total fluid, $\mathrm{mL}$ & $1731(532)$ & 1669 (683) & 0.573 \\
\hline Colloid, mL & $146(258)$ & $107(186)$ & 0.399 \\
\hline Blood loss, mL & $442(281)$ & $375(220)$ & 0.193 \\
\hline Urine output, $\mathrm{mL}$ & $167(121)$ & $224(177)$ & 0.069 \\
\hline
\end{tabular}

The incidences of BCR and pathological variables are presented in Table 2 . The number of patients who presented BCR was $28(45.2 \%)$ in the VA group and $25(39.1 \%)$ in the TIVA group, with no significant difference between the two groups. Similarly, the number of patients with positive radiographic progression did not differ between the two groups. Initial PSA levels, Gleason score, surgical margin status, pathological tumor stage, and lymph node metastasis were also similar in both groups.

BCR-free survival was identical between the VA and TIVA groups at any follow-up point after RALP (Figure 2).

Cox regression identified significant predictors of prostate cancer recurrence after RALP as colloid input (HR=1.002, 95\% CI:1.000-1.003; $\mathrm{P}=0.011)$, initial PSA level (HR=1.025, 95\% CI:1.007-1.044; $\mathrm{P}=0.006)$, and pathological tumor stage $3 b \quad(H R=4.217,95 \%$ CI:1.207-14.735; $\quad \mathrm{P}=0.024)$, but there was no dependence found on different general anesthetics (Table 3). 
Table 2. Incidence of recurrence and pathological variables.

\begin{tabular}{llll}
\hline Variables & $\begin{array}{l}\text { VA group } \\
(\mathrm{n}=62)\end{array}$ & $\begin{array}{l}\text { TIVA group } \\
(\mathrm{n}=64)\end{array}$ & $p$-value \\
\hline $\begin{array}{l}\text { BCR } \\
\text { Positive radiographic }\end{array}$ & $28(45.2 \%)$ & $25(39.1 \%)$ & 0.481 \\
progression & $5(8.1 \%)$ & $3(4.7 \%)$ & 0.488 \\
$\begin{array}{l}\text { Initial PSA level, ng/mL } \\
\text { Gleason score }\end{array}$ & $12.8(12.2)$ & $14.2(18.0)$ & 0.606 \\
6 & $18(29.0 \%)$ & $24(37.5 \%)$ & 0.474 \\
7 & $30(48.4 \%)$ & $30(46.9 \%)$ & \\
>=8 & $14(22.6 \%)$ & $10(15.6 \%)$ & \\
Surgical margin status & $30(48.4 \%)$ & $33(51.6 \%)$ & \\
negative & $32(51.6 \%)$ & $31(48.4 \%)$ & \\
positive & $30(48.4 \%)$ & $37(57.8 \%)$ & \\
Pathological Tumor stage & $27(43.6 \%)$ & $23(35.9 \%)$ & \\
2 & $5(8.1 \%)$ & $4(6.3 \%)$ & \\
3a & & & \\
3b & $60(96.8 \%)$ & $61(95.3 \%)$ & \\
Lymph node metastasis & $2(3.2 \%)$ & $3(4.7 \%)$ & \\
negative & & \\
positive & & & \\
\hline
\end{tabular}

Values are presented as means (SD) or numbers of patients (\%). VA, volatile anesthesia; TIVA, total intravenous anesthesia; BCR, biochemical recurrence; PSA, prostate specific antigen.

Table 3. Univariate and multivariate analysis of risk factors for $\operatorname{BCR}$ after $\operatorname{RALP}(n=126)$.

\begin{tabular}{|c|c|c|c|c|}
\hline \multirow[t]{2}{*}{ Variables } & \multirow{2}{*}{$\frac{\text { Univariate }}{\mathrm{HR}(95 \% \mathrm{CI})}$} & \multicolumn{2}{|r|}{ Multivariate } & \multirow[b]{2}{*}{$\begin{array}{l}\mathrm{P} \\
\text { value }\end{array}$} \\
\hline & & P value & HR $(95 \% \mathrm{CI})$ & \\
\hline Group & $0.940(0.548-1.613)$ & 0.823 & $1.227(0.660-2.283)$ & 0.518 \\
\hline Age, year & $1.002(0.968-1.038)$ & 0.904 & & \\
\hline Height, $\mathrm{m}^{2}$ & $0.969(0.924-1.017)$ & 0.204 & & \\
\hline Weight, kg & $1.005(0.977-1.033)$ & 0.741 & & \\
\hline \multicolumn{5}{|l|}{$\begin{array}{l}\text { ASA physical } \\
\text { status }\end{array}$} \\
\hline I & 1 & & & \\
\hline II & $1.171(0.680-2.018)$ & 0.570 & & \\
\hline $\begin{array}{l}\text { Anesthesia time, } \\
\text { min }\end{array}$ & $0.994(0.988-1.001)$ & 0.082 & & \\
\hline $\begin{array}{l}\text { Pneumoperiton } \\
\text { eum time, min }\end{array}$ & $0.993(0.985-1.000)$ & 0.053 & & \\
\hline \multicolumn{5}{|c|}{ Intraoperative input \& Output } \\
\hline Fluid input, $\mathrm{mL}$ & $1.000(1.000-1.001)$ & 0.677 & & \\
\hline $\begin{array}{l}\text { Colloid input, } \\
\mathrm{mL}\end{array}$ & $1.002(1.001-1.003)$ & 0.003 & $1.002(1.000-1.003)$ & $0.011^{*}$ \\
\hline $\begin{array}{l}\text { Urine output, } \\
\mathrm{mL}\end{array}$ & $1.001(1.000-1.002)$ & 0.331 & & \\
\hline Blood loss, mL & $1.001(1.000-1.002)$ & 0.412 & & \\
\hline $\begin{array}{l}\text { Initial PSA level, } \\
\mathrm{ng} / \mathrm{mL}\end{array}$ & $1.028(1.015-1.041)$ & $<0.001$ & $1.025(1.007-1.044)$ & $0.006^{*}$ \\
\hline \multicolumn{5}{|l|}{ Gleason score } \\
\hline 6 & 1 & & & \\
\hline 7 & $3.120(1.353-7.194)$ & 0.008 & $1.053(0.313-3.539)$ & 0.934 \\
\hline$>=8$ & $8.182(3.424-19.551)$ & $<0.001$ & $1.630(0.444-5.982)$ & 0.461 \\
\hline \multicolumn{5}{|c|}{ Surgical margin status } \\
\hline Negative & 1 & & & \\
\hline Positive & $2.967(1.648-5.341)$ & $<0.001$ & $1.806(0.893-3.653)$ & 0.100 \\
\hline \multicolumn{5}{|l|}{$\begin{array}{l}\text { Pathological } \\
\text { Tumor stage }\end{array}$} \\
\hline 2 & 1 & & & \\
\hline $3 a$ & $4.079(2.159-7.704)$ & $<0.001$ & $2.262(0.855-5.987)$ & 0.100 \\
\hline $3 b$ & $8.388(3.477-20.239)$ & $<0.001$ & $4.217(1.207-14.735)$ & $0.024^{*}$ \\
\hline \multicolumn{5}{|l|}{$\begin{array}{l}\text { Lymph node } \\
\text { metastasis }\end{array}$} \\
\hline Negative & 1 & & & \\
\hline Positive & $3.073(1.100-8.587)$ & 0.032 & $0.607(0.154-2.395)$ & 0.476 \\
\hline
\end{tabular}
volatile anesthetic agents can have a direct effect on tumor cells and induce mitogenesis, angiogenesis, and metastasis of tumors, which is associated with increased expression of insulin-like growth factor, vascular endothelial growth factor, and hypoxia-inducible factor (HIF) protein [24-27].

In contrast, propofol appears to increase the activity of cytotoxic T-lymphocytes [28] and not suppress NK cell activity in vitro [3]. In addition, propofol directly prevents HIF activation [29], and may exert anti-tumor effects mediated through inhibition of the cyclooxygenase pathway [30]. It has also been reported that propofol has an inhibitory effect on the sympathetic nervous system, which attenuates catecholamine release [31]. The nervous system is a primary actor in early and late cancer development. Many cancers (e.g., colon and prostate) present a specific growth pattern called "perineural invasion" which is driven by neurons [32]. The growth of some cancers, such as prostate cancer, pancreatic cancer, and breast cancer, is associated with "neurogenesis" and abundant infiltration of the tumor by the autonomic nervous system [33]. The prostate has a sympathetic nerve supply that is 5 or 6 times greater than that of the other chromaffin organs, making it particularly susceptible to these effects [34]. The stress response results from stimulation of the sympathetic nervous system, which enhances tumor growth through immunosuppression and betaadrenergic stimulation of tumor cells [33]. In animal studies, sympathectomy has been reported to slow the progression of cancer, and human retrospective data have indicated lower rates of recurrence and mortality among patients with cancer taking beta-blockers [35]. Thus, we envisaged favorable long-term oncologic 
outcomes in the TIVA group owing to the comparatively safer effects of propofol, such as the relative preservation of cellular immunity and inhibition of sympathetic activity. However, our results showed no difference in the rate of recurrence after RALP between the VA and TIVA groups. In addition, there was no difference between these groups after subgroup analysis of volatile anesthetics.

There have been many clinical studies on this topic, but these were retrospective studies. Previous studies in patients with colorectal and esophageal cancer showed better prognosis in patients receiving TIVA with propofol [10-12]. However, in studies of lung and breast cancer surgery, there were no differences in oncologic outcomes, which is consistent with the current results $[8,9,14,36]$. It has been shown that expression of catecholamine associated with stress, such as norepinephrine, promotes cell migration in colon, prostate, ovarian, and breast cancer cells [37]. Similarly, according to the type of cancer, volatile anesthetics or propofol may have markedly different influences on oncologic outcomes. To date, however, no studies have been conducted to compare the effects of volatile anesthetics or propofol on oncological outcomes according to the various cancer cell types. Therefore, more studies are required in this area.

While the impact of opioid use on recurrence is debatable, opioids such as fentanyl and morphine have been reported to promote poor oncologic outcomes in terms of immunity and angiogenesis [38, 39]. Regarding the unfavorable tumor microenvironment caused by opioids, intraoperative infusion of remifentanil may have affected the recurrence rate after RALP in our study. Although a previous study provided evidence that a low dose infusion of remifentanil does not affect cellular immunity status [40], this study targeted only healthy volunteers and did not include patients with reduced immunity or immunocompromised patients, such as patients with cancer. The dose was also lower than that typically administered during surgery. In animal models of breast cancer, early administration of morphine did not affect the growth of cancer cells, but morphine administered after cancer progression reduced the survival rate, as morphine directly acts on $\mu$-opioid receptors (MOR) expressed in the tumor, thereby promoting the growth of cancer cells [41]. In recent studies, it has been shown that the increased expression of MOR in patients with cancer is associated with worse prognosis. A recent mediation study showed that twice as much MOR is expressed in the tissues of patients with metastatic lung cancer compared to patients with lung cancer [42]. In addition, a study of patients with advanced prostate cancer indicated a significantly shorter progressionfree survival in patients with higher MOR expression in cancer tissues and greater morphine requirements after cancer diagnosis [43]. Considering the impact of opioids on cancer growth, the continuous infusion of remifentanil in both groups could have been another confounding factor for the negative outcomes in the current study.

Finally, in previous reports that showed favorable effects of propofol on oncologic outcomes, most cases were combined with epidural analgesia, except one that involved patients undergoing gastrectomy [8, 9, 13, 14, 36]. However, in recent studies which did not apply regional or neuraxial analgesia, there was no benefit of propofol-based TIVA for long-term oncologic outcomes after non-small cell lung cancer and breast cancer surgery [10-12]. The majority of studies which showed better oncologic outcomes associated with propofol-based TIVA applied regional or neuraxial analgesia for pain control, and consequently, small dose of opioids were used during surgery. Opioids may therefore be a significant confounding factor for confirming the influence of propofol on oncologic outcomes. Thus, there are many difficulties in obtaining accurate results, and well-controlled prospective clinical studies of these confounding variables are required.

There are several limitations to the current study. First, this is a retrospective study. However, the selection bias may be negligible because only randomly assigned patients were included and there was marginal difference in the surgical techniques owing to the relatively short study period from November 2010 to March 2012. Second, our sample size was limited by the size of the original PONV and IOP trials, and follow-up data were not available for 2 patients. Our analysis was thus restricted to 64 patients in the TIVA group and 62 patients in the VA group. Although it may seem that the sample size is limited, we consider this to be a sufficiently influential outcome, since this study was based on data from a period of 7-9 years over which patients were enrolled and randomly assigned. Third, the volatile agents in the two original trials were different (desflurane in the PONV trial and sevoflurane in the IOP trial). However, no differences were found between the two volatile anesthetics following subgroup analysis. Finally, anesthetic induction was also performed using a bolus injection of propofol in the VA group. However, the influence of small amounts of propofol during the induction period in the VA group is considered to be insignificant based on the primary outcomes of previous studies where intraoperative IOP and PONV were significantly better in the TIVA group. 


\section{Conclusions}

This study was the first report on the long-term follow-up of prostate cancer recurrence after RALP under TIVA with propofol/remifentanil and VA with sevoflurane or desflurane/remifentanil. Our findings demonstrate that both TIVA with propofol/ remifentanil and VA with sevoflurane or desflurane/ remifentanil have comparable effects on oncologic outcomes in patients undergoing RALP. Additionally, we believe that the type of cancer should be considered as a potential factor in the clinical decision of the choice of anesthetic for cancer surgery. However, for further validation of our findings, additional prospective trials should be undertaken that will closely monitor and control the influence of opioids on oncologic outcomes.

\section{Abbreviations}

RALP: robot-assisted laparoscopic radical prostatectomy; TIVA: total intravenous anesthesia; VA: volatile anesthetics; PONV: postoperative nausea and vomiting; IOP: intraocular pressure; BCR: biochemical recurrence; $\mathrm{CO}_{2}$ : carbon dioxide; MAP: mean arterial pressure; BIS: bispectral index score; PSA: prostate specific antigen; HRs: hazard ratios; CIs: confidence intervals; HIF: hypoxia-inducible factor; MOR: $\mu$-opioid receptors.

\section{Acknowledgments}

The authors thank Medical Illustration and Design, a part of the Medical Research Support Services of Yonsei University College of Medicine, for all artistic support related to this work.

\section{Author Contributions}

N.Y.K and W.C.J. contributed equally to this work. N.Y.K. and W.C.J. contributed to the study design and conduct, data analysis, and manuscript writing. Y.D.C. contributed to the methodology and project administration. J.H.H. contributed to the data analysis. S.N. participated in data curation. Y.C.Y. participated as the corresponding author and supervised the overall study and drafting of the manuscript.

\section{Ethics Committee Approval and Patient Consent}

Ethics approvals were obtained from the institutional review board and hospital research ethics committee (Yonsei University Health System, Seoul, Korea; IRB protocol No. 4-2019-0313, approved on 23 May, 2019). The need for informed consent from the patients was waived.

\section{Competing Interests}

The authors have declared that no competing interest exists.

\section{References}

1. Byrne K, Levins KJ, Buggy DJ. Can anesthetic-analgesic technique during primary cancer surgery affect recurrence or metastasis? Can J Anaesth 2016; 63(2):184-92.

2. Stollings LM, Jia LJ, Tang P, Dou H, Lu B, Xu Y. Immune Modulation by Volatile Anesthetics. Anesthesiology 2016; 125(2):399-411.

3. Melamed R, Bar-Yosef S, Shakhar G, Shakhar K, Ben-Eliyahu S. Suppression of natural killer cell activity and promotion of tumor metastasis by ketamine, thiopental, and halothane, but not by propofol: mediating mechanisms and prophylactic measures. Anesth Analg 2003; 97(5):1331-9.

4. Ke JJ, Zhan J, Feng XB, Wu Y, Rao Y, Wang YL. A comparison of the effect of total intravenous anaesthesia with propofol and remifentanil and inhalational anaesthesia with isoflurane on the release of pro- and anti-inflammatory cytokines in patients undergoing open cholecystectomy. Anaesth Intensive Care 2008; 36(1):74-8.

5. Dubowitz JA, Sloan EK, Riedel BJ. Implicating anaesthesia and the perioperative period in cancer recurrence and metastasis. Clin Exp Metastasis 2018; 35(4):347-58.

6. Soltanizadeh S, Degett TH, Gogenur I. Outcomes of cancer surgery after inhalational and intravenous anesthesia: A systematic review. J Clin Anesth 2017; 42:19-25.

7. Lee JH, Kang SH, Kim Y, Kim HA, Kim BS. Effects of propofol-based total intravenous anesthesia on recurrence and overall survival in patients after modified radical mastectomy: a retrospective study. Korean J Anesthesiol 2016; 69(2):126-32.

8. Wigmore TJ, Mohammed K, Jhanji S. Long-term Survival for Patients Undergoing Volatile versus IV Anesthesia for Cancer Surgery: A Retrospective Analysis. Anesthesiology 2016; 124(1):69-79.

9. Enlund M, Berglund A, Andreasson K, Cicek C, Enlund A, Bergkvist L. The choice of anaesthetic--sevoflurane or propofol--and outcome from cancer surgery: a retrospective analysis. Ups J Med Sci 2014; 119(3):251-61.

10. Kim MH, Kim DW, Kim JH, Lee KY, Park S, Yoo YC. Does the type of anesthesia really affect the recurrence-free survival after breast cancer surgery? Oncotarget 2017; 8(52):90477-87.

11. Yoo S, Lee HB, Han W, Noh DY, Park SK, Kim WH, et al. Total Intravenous Anesthesia versus Inhalation Anesthesia for Breast Cancer Surgery: A Retrospective Cohort Study. Anesthesiology 2019; 130(1):31-40.

12. Oh TK, Kim K, Jheon S, Lee J, Do SH, Hwang JW, et al. Long-Term Oncologic Outcomes for Patients Undergoing Volatile Versus Intravenous Anesthesia for Non-Small Cell Lung Cancer Surgery: A Retrospective Propensity Matching Analysis. Cancer Control 2018; 25(1):1073274818775360.

13. Zheng $\mathrm{X}$, Wang $\mathrm{Y}$, Dong $\mathrm{L}$, Zhao $\mathrm{S}$, Wang $\mathrm{L}$, Chen $\mathrm{H}$, et al. Effects of propofol-based total intravenous anesthesia on gastric cancer: a retrospective study. Onco Targets Ther 2018; 11:1141-8.

14. Wu ZF, Lee MS, Wong CS, Lu CH, Huang YS, Lin KT, et al. Propofol-based Total Intravenous Anesthesia Is Associated with Better Survival Than Desflurane Anesthesia in Colon Cancer Surgery. Anesthesiology 2018; 129(5):932-41.

15. Jemal A, Murray T, Samuels A, Ghafoor A, Ward E, Thun MJ. Cancer statistics, 2003. CA Cancer J Clin 2003; 53(1):5-26.

16. Yamashita H, Shuman L, Warrick JI, Raman JD, Degraff DJ. Androgen represses opioid growth factor receptor (OGFR) in human prostate cancer LNCaP cells and OGFR expression in human prostate cancer tissue. Am J Clin Exp Urol 2018; 6(4):164-71.

17. Yoo YC, Bai SJ, Lee KY, Shin S, Choi EK, Lee JW. Total intravenous anesthesia with propofol reduces postoperative nausea and vomiting in patients undergoing robot-assisted laparoscopic radical prostatectomy: a prospective randomized trial. Yonsei Med J 2012; 53(6):1197-202.

18. Yoo YC, Shin S, Choi EK, Kim CY, Choi YD, Bai SJ. Increase in intraocular pressure is less with propofol than with sevoflurane during laparoscopic surgery in the steep Trendelenburg position. Can J Anaesth 2014; 61(4):322-9.

19. Coetzee JF, Glen JB, Wium CA, Boshoff L. Pharmacokinetic model selection for target controlled infusions of propofol. Assessment of three parameter sets. Anesthesiology 1995; 82(6):1328-45.

20. Minto CF, Schnider TW, Shafer SL. Pharmacokinetics and pharmacodynamics of remifentanil. II. Model application. Anesthesiology 1997; 86(1):24-33.

21. Markovic SN, Knight PR, Murasko DM. Inhibition of interferon stimulation of natural killer cell activity in mice anesthetized with halothane or isoflurane. Anesthesiology 1993; 78(4):700-6.

22. Mitsuhata H, Shimizu R, Yokoyama MM. Suppressive effects of volatile anesthetics on cytokine release in human peripheral blood mononuclear cells. Int J Immunopharmacol 1995; 17(6):529-34.

23. Weimann J. Toxicity of nitrous oxide. Best Pract Res Clin Anaesthesiol 2003; 17(1):47-61.

24. Luo X, Zhao H, Hennah L, Ning J, Liu J, Tu H, et al. Impact of isoflurane on malignant capability of ovarian cancer in vitro. Br J Anaesth 2015; 114(5):831-9. 
25. Xu YJ, Chen WK, Zhu Y, Wang SL, Miao CH. Effect of thoracic epidural anaesthesia on serum vascular endothelial growth factor $C$ and cytokines in patients undergoing anaesthesia and surgery for colon cancer. Br J Anaesth 2014; 113 Suppl 1:i49-55.

26. Shi QY, Zhang SJ, Liu L, Chen QS, Yu LN, Zhang FJ, et al. Sevoflurane promotes the expansion of glioma stem cells through activation of hypoxia-inducible factors in vitro. Br J Anaesth 2015; 114(5):825-30.

27. Benzonana LL, Perry NJ, Watts HR, Yang B, Perry IA, Coombes C, et al. Isoflurane, a commonly used volatile anesthetic, enhances renal cancer growth and malignant potential via the hypoxia-inducible factor cellular signaling pathway in vitro. Anesthesiology 2013; 119(3):593-605.

28. Kushida A, Inada T, Shingu K. Enhancement of antitumor immunity after propofol treatment in mice. Immunopharmacol Immunotoxicol 2007; 29(3-4):477-86.

29. Huang H, Benzonana LL, Zhao H, Watts HR, Perry NJ, Bevan C, et al. Prostate cancer cell malignancy via modulation of HIF-1alpha pathway with isoflurane and propofol alone and in combination. Br J Cancer 2014; 111(7):1338-49.

30. Inada T, Kubo K, Shingu K. Possible link between cyclooxygenase-inhibiting and antitumor properties of propofol. J Anesth 2011; 25(4):569-75.

31. Han L, Fuqua S, Li Q, Zhu L, Hao X, Li A, et al. Propofol-induced Inhibition of Catecholamine Release Is Reversed by Maintaining Calcium Influx. Anesthesiology 2016; 124(4):878-84.

32. Forget P, Aguirre JA, Bencic I, Borgeat A, Cama A, Condron C, et al. How Anesthetic, Analgesic and Other Non-Surgical Techniques During Cancer Surgery Might Affect Postoperative Oncologic Outcomes: A Summary of Current State of Evidence. Cancers (Basel) 2019; 11(5).

33. Magnon C, Hall SJ, Lin J, Xue X, Gerber L, Freedland SJ, et al. Autonomic nerve development contributes to prostate cancer progression. Science 2013; 341(6142):1236361.

34. Rodrigues AO, Machado MT, Wroclawski ER. Prostate innervation and local anesthesia in prostate procedures. Rev Hosp Clin Fac Med Sao Paulo 2002; 57(6):287-92

35. Na Z, Qiao X, Hao X, Fan L, Xiao Y, Shao Y, et al. The effects of beta-blocker use on cancer prognosis: a meta-analysis based on 319,006 patients. Onco Targets Ther 2018; 11:4913-44.

36. Jun IJ, Jo JY, Kim JI, Chin JH, Kim WJ, Kim HR, et al. Impact of anesthetic agents on overall and recurrence-free survival in patients undergoing esophageal cancer surgery: A retrospective observational study. Sci Rep 2017; 7(1):14020.

37. Tilan J, Kitlinska J. Sympathetic Neurotransmitters and Tumor Angiogenesis-Link between Stress and Cancer Progression. J Oncol 2010; 2010:539706.

38. Afsharimani B, Cabot P, Parat MO. Morphine and tumor growth and metastasis. Cancer Metastasis Rev 2011; 30(2):225-38.

39. Grandhi RK, Lee S, Abd-Elsayed A. Does Opioid Use Cause Angiogenesis and Metastasis? Pain Med 2017; 18(1):140-51.

40. Cronin AJ, Aucutt-Walter NM, Budinetz T, Bonafide CP, DiVittore NA, Gordin V, et al. Low-dose remifentanil infusion does not impair natural killer cell function in healthy volunteers. Br J Anaesth 2003; 91(6):805-9.

41. Nguyen J, Luk K, Vang D, Soto W, Vincent L, Robiner S, et al. Morphine stimulates cancer progression and mast cell activation and impairs survival in transgenic mice with breast cancer. Br J Anaesth 2014; 113 Suppl 1:i4-13.

42. Singleton PA, Mirzapoiazova T, Hasina R, Salgia R, Moss J. Increased mu-opioid receptor expression in metastatic lung cancer. Br J Anaesth 2014; 113 Suppl 1:i103-8.

43. Zylla D, Gourley BL, Vang D, Jackson S, Boatman S, Lindgren B, et al. Opioid requirement, opioid receptor expression, and clinical outcomes in patients with advanced prostate cancer. Cancer 2013; 119(23):4103-10. 